\title{
PENGARUH BUDAYA ASING DALAM KEPEMIMPINAN NASIONAL DI MASA MENDATANG
}

\author{
Gerend Christopher, Muhammad Izzatul Fauzan Hasibuan, Verdhian Nahwa Saputra, \& \\ Violeta Valencia \\ Institut Teknologi Bandung \\ Email: 10120084@mahasiswa.itb.ac.id
}

\begin{abstract}
Abstrak
Berkembangnya internet di zaman ini telah membuka ilmu pengetahuan dan informasi di seluruh dunia kepada masyarakat secara cepat dan masif. Setiap individu dapat melihat apa yang terjadi di belahan dunia lain hanya dalam hitungan beberapa detik. Dengan adanya kemudahan akses tersebut, pertukaran informasi menjadi lebih sering terjadi. Hal tersebut membuka peluang untuk masingmasing individu menjadi tertarik dan terpengaruh dengan budaya asing tanpa adanya batas. Bila dibiarkan lebih jauh, hal tersebut akan berdampak pada banyak hal, salah satunya terhadap kepemimpinan nasional di masa yang akan datang. Dengan adanya penyaluran gelombang informasi yang masif tersebut, secara tidak langsung sifat dari setiap individu nasional akan terpengaruh, baik secara positif maupun negatif, dan alur kepemimpinan di masa depan akan berubah. Dalam mencegah perubahan yang masif ini dibutuhkan adanya pemahaman untuk setiap individu tentang pentingnya memelihara budaya dan mengolah informasi yang diterima.
\end{abstract}

Kata Kunci: Kepemimpinan nasional, Budaya asing, Informasi

\begin{abstract}
The development of the internet in this era has opened up knowledge and information around the world to the public quickly and massively. Any individual can see what is happening in the other world in just a few seconds. With the ease of access, the exchange of information becomes more frequent. This opens up opportunities for each individual to be interested and influenced by foreign cultures without any boundaries. If allowed to go further, this will have an impact on many things, one of which will affect national leadership in the future. With this massive wave of information, indirectly the nature of every national individual will be affected, both positively and negatively, and the path of future leadership will change. Preventing this enormous change requires understanding for each individual about the importance of maintaining culture and processing the information received
\end{abstract}

Keywords: National leadership, Foreign culture, Information

\section{PENDAHULUAN}

Kepemimpinan adalah suatu kemampuan yang dapat membaca dan memahami suatu keberagaman, keunikan, dan perbedaan antara individu yang satu dengan individu yang lainnya (Dewantara \& Nurgiansah, 2021a). Perbedaan yang muncul dari tiap individu tersebut memberikan suatu dampak yang sangat besar, yaitu setiap manusia sangatlah dibutuhkan, karena peran yang dipegang dari tiap-tiap individu tersebut sangatlah berbeda. Oleh karena itu, seorang pemimpin diharapkan mampu memahami peranan masing-masing dari tiap individu tersebut dan bisa memberikan suatu perubahan yang besar dari pengikutnya (Dewantara et al., 2021).

Kemudian, tolak ukur suatu pemimpin yang baik bukanlah kecerdasan yang luar biasa, fisik yang kekar, atau kemampuan untuk meyakinkan orang lain, melainkan kemampuan meningkatkan nilai dan kualitas dari individu yang dipimpinnya. Melalui penjelasan dan pemaparan yang disajikan pada bagian di atas timbulah suatu pertanyaan dari masing-masing individu tersebut. Bagaimanakah bentuk standar kepemimpinan nasional yang dijunjung oleh Negara Kesatuan Republik Indonesia? Menurut (Pokja Pimnas, 2010b) 
pada paper (Iwan Nugroho, 2010) (Dewantara \& Nurgiansah, 2021b) Sistem Kepemimpinan Nasional yang dibutuhkan oleh Negara Kesatuan Republik Indonesia adalah sistem kepemimpinan nasional yang dapat menjalankan visi pembangunan nasional dilandasi paradigma nasional dengan kemampuan (i) memantapkan integrasi bangsa dan solidaritas nasional, (ii) mementingkan stabilitas nasional untuk meningkatkan rasa kebangsaan, (iii) memahami perubahan dan melaksanakan pembaharuan dalam manajemen pemerintahan dan (iv) menggunakan pendekatan politik dalam upaya pencarian solusi untuk menangani permasalahan dalam kehidupan masyarakat.

Akan tetapi, perwujudan

Kepemimpinan Nasional yang dipaparkan pada bagian sebelumnya mengalami intervensi atau gangguan dari media komunikasi yang digunakan saat ini, yaitu internet. Alasannya adalah internet sangat mudah dan murah untuk diakses (Rachman, Nurgiansah, et al., 2021).

$$
\text { Internet juga memudahkan }
$$

penyebaran informasi dan ilmu pengetahuan di seluruh dunia kepada masyarakat dengan sangat cepat. Terlepas dari informasi berupa berita-berita internasional, informasi juga dapat berupa budaya yang terkadang tanpa disadari telah diterima. Oleh sebab itu, budaya atau budaya asing bisa memengaruhi kehidupan seseorang, baik dari sisi positif, maupun negatif (Rachman, Ryan, et al., 2021).

Informasi budaya asing yang tidak dikelola atau disaring dengan baik juga dapat menyebabkan budaya asing yang tidak sesuai dengan nilai-nilai luhur dapat masuk. Pengaruh budaya asing yang negatif bisa berdampak buruk bagi penerima yang tidak bijak, khususnya muda-mudi di bangsa Indonesia yang secara usia masih bisa dikatakan labil. Perihal ini akan berdampak pada pandangan putra-putri bangsa yang akan berpengaruh pada kepemimpinan hidupnya dan kepemimpinan nasional di masa mendatang (Nurgiansah, 2020a) (Nurgiansah, 2020d).

Oleh karena itu, kami sebagai peneliti akan meneliti mengenai pengaruh budaya asing dalam kepemimpinan nasional di masa mendatang dan mencari solusi untuk meningkatkan kesadaran masyarakat terhadap pentingnya memelihara budaya tradisional di masa mendatang serta meningkatkan kemampuan masyarakat dalam mengolah informasi terkait budaya asing.

\section{METODE PENELITIAN}

Teknik pengumpulan data yang akan diterapkan adalah menggunakan metode penelitian kuantitatif yang dilakukan dengan cara pengambilan sampel dengan melakukan survei untuk mengetahui kesadaran masyarakat terhadap pentingnya memelihara budaya dan mengetahui kesadaran masyarakat terkait informasi asing.

\section{HASIL PENELITIAN DAN PEMBAHASAN Hasil Penelitian}

Berdasarkan survei yang
dilaksanakan, kisaran usia yang menyatakan pendapat dan pikiran adalah anak-anak berusia 17-21 tahun dari berbagai daerah di Indonesia. Usia partisipan berada pada rentang generasi Z, ini menunjukkan hasil survei yang diberikan berupa pendapat atau pemikiran para calon pemimpin nasional tentang pandangan terhadap masa depan Indonesia. 


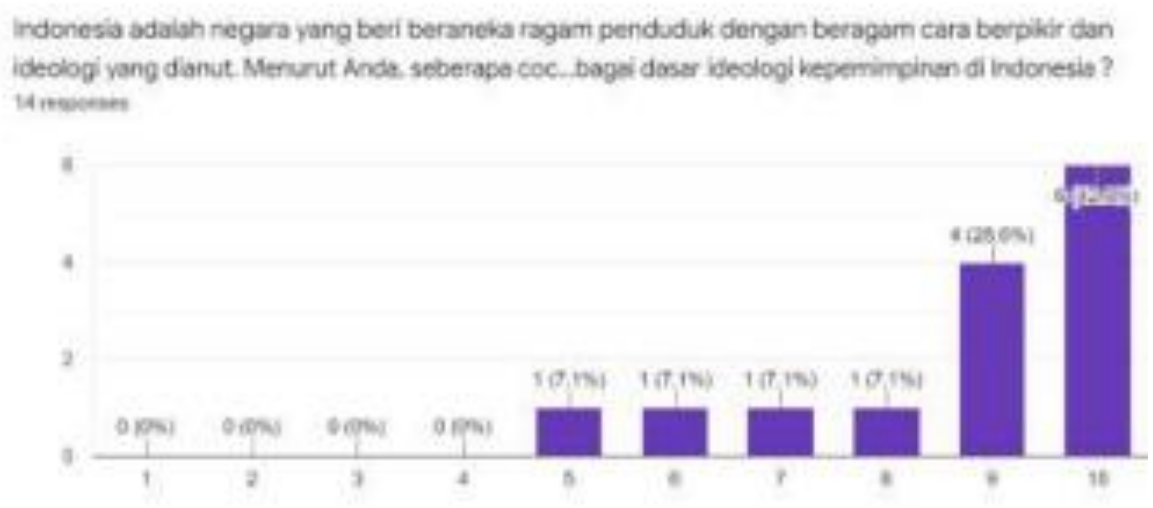

\section{Gambar 1. Tingkat Kecocokan Ideologi Pancasila terhadap Ideologi Kepemimpinan Indonesia}

Berdasarkan hasil survei yang diberikan, dari 0 hingga 10 tingkat kecocokan ideologi Pancasila sebagai dasar ideologi kepemimpinan di Indonesia, semua partisipan memberikan nilai di atas atau sama dengan 5. Selain itu, $71.5 \%$ hasil survei memberikan nilai 9 atau 10 . Oleh karena itu, dapat disimpulkan ideologi Pancasila masih dirasa cocok oleh kaum generasi $\mathrm{Z}$ dari berbagai daerah sebagai dasar ideologi kepemimpinan di Indonesia.

Selain itu, selama pengolahan hasil survey, peneliti juga mencari data mengenai bentuk-bentuk budaya lain yang dapat memberikan suatu pengaruh atau dampak yang cukup besar selain ideologi Pancasila. Hasil survey yang diberikan memperoleh suatu respons berupa Negara Cina memiliki pengaruh terbesar dalam pergeseran nilai - nilai kepemimpinan nasional yang akan dipegang oleh Bangsa Indonesia. Negara Amerika Serikat dan Jepang mengikuti di belakangnya.

\section{Pembahasan}

Negara China sebagai negara yang memiliki jumlah penduduk terbesar tentu akan memberikan kekhawatiran berupa nilai-nilai budaya yang akan ditanamkan pada Negara Indonesia (Nurgiansah, 2020b)(Nurgiansah, 2021g). Salah satu budaya yang menjadi perhatian penuh pada kasus ini adalah budaya komunis. Komunis menurut Frederick Engel pada buku The Principles of Communism memberikan penjelasan bahwa komunisme adalah doktrin pada suatu kondisi kebebasan di proletariat. Proletariat ini juga dijelaskan pada buku yang sama memberikan suatu penjelasan bahwa Proletariat adalah kelas di masyarakat yang memiliki bentuk pekerjaan sebagai buruh atau pekerja kasar, sehingga masyarakat ini tidak kesejahteraan malah memiliki duka (Nurgiansah, 2021e)(Nurgiansah, 2021b).

Kondisi ini pernah terjadi di Indonesia pada tahun 1950-1965 yang memunculkan suatu pemberontakan yang sangat besar yang lebih dikenal dengan G30'S PKI. Alasan pemberontakan ini menurut (Michael, 2017) (Nurgiansah, 2021a) bahwa kelas buruh pada zaman itu ingin melakukan penghapusan hak milik pada burjouis. Hal ini dapat disebabkan oleh besarnya ketimpangan sosial dari masyarakat buruh dan burjouis dari sisi kaum buruh dalam hal kesejahteraan dan lain - lain. Akan tetapi, masalah ini dapat diselesaikan dengan peranan Soeharto dalam operasi sapu bersihnya selama periode kepemimpinannya sebagai presiden (Nurgiansah, 2021f). Oleh karena itu, peneliti sudah melakukan suatu survey yang hasilnya dapat dikaitkan dengan hasil di bawah ini: 


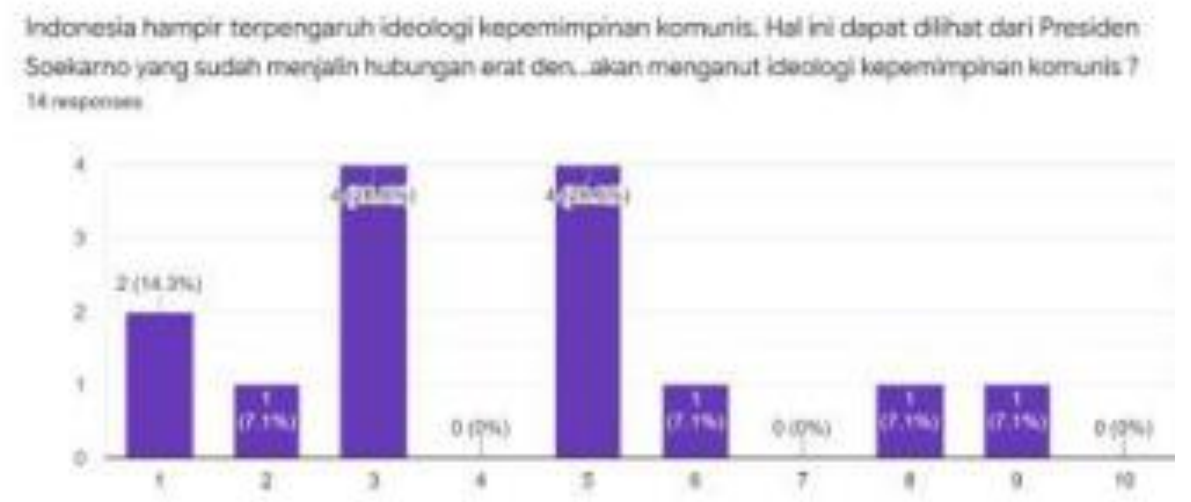

\section{Gambar 2. Tingkat Kecendrungan Indonesia Menganut Ideologi Komunis}

Meskipun dapat memberikan kekhawatiran, berdasarkan hasil survei yang diberikan, rata rata memberikan pendapat bahwa Indonesia memiliki kemungkinan kecil untuk kembali menganut ideologi komunis (Nurgiansah, 2021c) (Nurgiansah, 2021d). Hal ini diperkuat dengan alasan bahwa ideologi komunis yang pernah dianut pada zaman dahulu kurang relevan bagi bangsa Indonesia yang memiliki keanekaragaman budaya dan latar belakang. Selain itu, Indonesia juga sudah memegang teguh nilai-nilai Pancasila yang menyatukan keragaman tersebut. Selain itu, ideologi komunis sendiri sudah memiliki konotasi yang buruk di telinga masyarakat Indonesia yang disebabkan tragedi berdarah sewaktu pemberontakan Muso dan G30'S PKI (Nurgiansah, 2020c).

Kemudian, kebudayaan asing yang memberikan dampak negatif pada bangsa Indonesia juga dapat memberikan suatu dampak positif yang luar biasa. Melalui kuesioner yang disebarkan kepada Masyarakat Indonesia memberikan suatu gambaran ada beberapa budaya yang dapat diterapkan oleh Masyarakat Indonesia:

1. Kebudayaan Hakko Ichiu yang merupakan salah satu bentuk kebudayaan Jepang yang memiliki manfaat dalam peningkatan persatuan dan penguaran rasa nasionalisme
Bangasa Indonesia (Sakti \& Hartanto, 2020) (Rahmelia, 2021)(Sakinah \& Dewi, 2021).

2. Menyerap konsep Negara Cina saat ini yang sudah menggabungkan konsep komunisme dan kapitalisme dalam satu payung yang sama. Konsep Komunisme atau Sosialis digunakan dalam pembuatan BUMN yang diwadahi oleh negara, sehingga pengelolaan sumber daya alam yang vital dan penting oleh masyarakat dapat dikelola secara adil dan lebih baik oleh negara. Selain itu, konsep Kapitalisme diterapkan untuk memacu masyarakat Cina untuk bekerja dan melakukan lebih baik dengan besar ketimpangan sosial yang sudah diperhitungkan oleh negara.

3. Kebebasan berpendapat yang diberikan oleh Amerika Serikat kepada masyarakatnya. Konsep ini sudah diserap oleh Bangsa Indonesia melalui penggunaan lembaga negara, seperti DPR, DPD, dan MPR. Selain itu, Indonesia juga membuat suatu pemilu secara langsung untuk memilih wakilnya.

Oleh sebab itu, pengaruh asing perlu dimanfaatkan untuk kepentingan kepemimpinan nasional di masa mendatang. Cara yang efektif dalam menerapkan nilai-nilai Pancasila dalam 
model kepemimpinan dengan memanfaatkan pengaruh asing adalah mengkolaborasikan pengaruh asing yang positif, seperti keterbukaan pikiran untuk meningkatkan kepemimpinan. Akan tetapi, dengan mengambil nilai-nilai positif yang ditawarkan, Pancasila tidak ditinggalkan, tetapi Pancasila tetap menjadi dasar negara dan tetap menjadi pokok ideologi dasar Indonesia.

\section{KESIMPULAN}

Berdasarkan hasil dan pembahasan, dapat disimpulkan bahwa Kebudayaan Asing merupakan salah satu bentuk pengaruh yang memiliki dua sisi bagi keberjalanan kepemimpinan di Indonesia. Sisi pertama adalah sisi yang sangat berbahaya karena dampak yang diberikan, seperti komunisme dan sisi lain adalah sisi yang sangat berguna bagi kehidupan Bangsa Indonesia yang berupa kebebasan berpendapat yang diberikan kepada masyarakat untuk pemangku jabatan. Kebebasan berpendapat ini memberikan kesempatan baru bagi para pemimpin untuk mengetahui hal utama dan yang benar - benar dibutuhkan oleh Masyarakat Indonesia.

Pancasila sudah menjadi ideologi yang bulat dan tidak bisa diganggu gugat oleh pihak lainnya, karena Pancasila sudah menggambarkan seluruh aspek kehidupan dari Bangsa Indonesia itu sendiri. Selain itu, Pancasila juga sudah menjadi dasar atau acuan dari kepemimpinan nasional yang sesuai dengan keinginan oleh Bangsa Indonesia itu sendiri.

Kebudayaan yang masuk ke Negara Indonesia terlebih dahulu disaring terlebih dahulu dengan memperhatikan nilai-nilai Pancasila, karena kebudayaan yang baik akan sesuai dengan nilai-nilai Pancasila. Oleh karena itu, kecerdasan berpikir sangat diperlukan dalam mengolah permasalahan ini.

\section{DAFTAR PUSTAKA}

Depree, M. (1989). Leadership Is an Art. New York: Doubleday.

Dewantara, J. A., Hermawan, Y., Yunus, D., Prasetiyo, W. H., Efriani, Arifiyanti, F., \& Nurgiansah, T. H. (2021). Anti-Corruption Education as an Effort to Form Students With Character Humanist and Law-Compliant. Jurnal Civics: Media Kajian Kewarganegaraan, 18(1), 70-81. Dewantara, J. A., \& Nurgiansah, T. H. (2021a). Peningkatan Keaktifan Belajar Melalui Penerapan Model Picture And Picture Dalam Pembelajaran PPKn di Sekolah Dasar. Jurnal Publikasi Pendidikan, 11(3), 234-241.

Dewantara, J. A., \& Nurgiansah, T. H. (2021b). Strengthening Pancasila Values During the Covid19 Pandemic. Edukatif: Jurnal Ilmu Pendidikan, 3(4), 2411-2417.

Engels, F. (2012). "Principles of Communism" (1847). In J. Isaac (Ed.), The Communist Manifesto (pp. 52-72). New Haven: Yale University Press. https://doi.org/10.12987/9780300163209-006

Michael, T. (2016). Korelasi Komunisme Dalam Demokrasi di Indonesia. Refleksi Hukum: Jurnal Ilmu Hukum, 1(1), 15-28.

Nugroho, I. (2011). Peran Kepemimpinan Nasional dalam Implementasi Nilai-nilai Pancasila sebagai Falsafah Hidup Bangsa dan Pembangunan Nasional. Paper dalam Kongres Pancasila ke, 3.

Nurgiansah, T. H. (2020a). Build An Attitude of Nationalism Students At SDN 7 Kadipaten With The Method of Discusion In The Subject PPKn. Jurnal Serunai Pendidikan Pancasila Dan Kewarganegaraan STKIP Budi Daya Binjai, 9(1), 1-11.

Nurgiansah, T. H. (2020b). Fenomena Prostitusi Online Di Kota Yogyakarta Dalam Persfektif Nilai Kemanusiaan Yang Adil Dan Beradab. Jurnal Kewarganegaraan, 17(1), 27-34. https://doi.org/10.24114/jk.v17i1.14208 
Nurgiansah, T. H. (2020c). Filsafat Pendidikan. In Banyumas: CV Pena Persada.

Nurgiansah, T. H. (2020d). Pelatihan Penulisan Artikel Ilmiah Bagi Mahasiswa PPKn Universitas PGRI Yogyakarta. JNPM: Jurnal Nasional Pengabdian Masyarakat, 1(1), 16-23.

Nurgiansah, T. H. (2021a). Partisipasi Politik Masyarakat Sleman di Masa Pandemi Covid-19 dalam Konteks Pendidikan Kewarganegaraan. Jurnal Civic Hukum, 6(1), 1-9.

Nurgiansah, T. H. (2021b). Pelatihan Penelitian Tindakan Kelas Bagi Guru Pendidikan Kewarganegaraan Di Sekolah Menengah Atas Se-Kabupaten Bantul. BERNAS: Jurnal Pengabdian Kepada Masyarakat, 2(1), 28-33. https://doi.org/10.31949/jb.v2i1.566

Nurgiansah, T. H. (2021c). Pemanfaatan E-Learning Dalam Pembelajaran Pendidikan Kewarganegaraan. JINTECH: Journal of Information Technology, 2(2), 138-146.

Nurgiansah, T. H. (2021d). Pendidikan Pancasila. In Solok: CV Mitra Cendekia Media.

Nurgiansah, T. H. (2021e). Pendidikan Pancasila Sebagai Upaya Membentuk Karakter Jujur. Jurnal Pendidikan Kewarganegaraan Undiksha, 9(1), 33-41.

Nurgiansah, T. H. (2021f). Petuah Pendidikan Kewarganegaraan Dalam Kontestasi Politik. AoEJ: Academy of Education Journal, 12(1), 39-47.

Nurgiansah, T. H. (2021g). The Role of Citizenship Education in Building Bantul Community Political Participation in The Pandemic Covid 19. Prosiding Seminar Nasional Pendidikan Dan Kewirausahaan, 4(1), 1-4.

Rachman, F., Nurgiansah, T. H., \& Kabatiah, M. (2021). Profilisasi Pendidikan Kewarganegaraan dalam Kurikulum Pendidikan Indonesia. Edukatif: Jurnal Ilmu Pendidikan, 3(5), 29702984.

Rachman, F., Ryan, T., Kabatiah, M., Batubara, A., Pratama, F. F., \& Nurgiansah, T. H. (2021). Pelaksanaan Kurikulum PPKn pada Kondisi Khusus Pandemi Covid-19. Jurnal Basicedu, 5(6), 5682-5691.

Rahmelia, S. (2021). Pemaknaan Mahasiswa Terhadap Narasi Konflik Beragama. Jurnal Kewarganegaraan, 5(1), 45-54.

Sakinah, R. N., \& Dewi, D. A. (2021). Implementasi Nilai-Nilai Pancasila Sebagai Karakter Dasar Para Generasi Muda Dalam Menghadapi Era Revolusi Industrial 4 . 0. Jurnal Kewarganegaraan, 5(1), 152-167.

Sakti, R. O., \& Hartanto, S. (2020). Meningkatkan Prestasi Belajar Ppkn Dengan Menggunakan Model Brain Based Learning. Jurnal Kewarganegaraan, 4(1), 38-44. https://journal.upy.ac.id/index.php/pkn/article/view/1171 